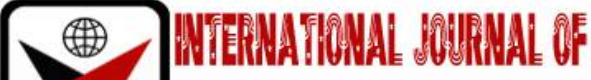

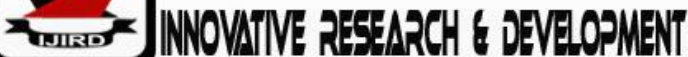

ISSN 2278 - 0211 (Online)

\section{Teacher Factors That Create a Dilemma in the Implementation of Learners' Psychomotor Curriculum Activities in the Early Childhood Development Education}

Arthur Ahinda Avosa
Teacher, Department of Early Childhood and Special Needs Education,
Jaramogi Oginga Oginga University of Science and Technology, Kenya
Dr. Odongo Charles Benson
Senior Lecturer, Department of Early Childhood and Special Needs Education,
Jaramogi Oginga Odinga University of Science and Technology, Kenya
Dr. Mwebi Benard
Lecturer, Department of Educational Management and Planning,
Jaramogi Oginga Odinga University of Science and Technology, Kenya

\section{Abstract:}

Psychomotor activities that are especially conducted outside the usual classroom environment assist in addressing areas of child's physical well-being, social-emotional learning and having an in-depth level of commitment, learning and improved educational performance. Some studies have sought to find out factors that hinder learners' involvement in outdoor activities but pre-primary teachers' dilemma in implementing of learners psychomotor or outdoor activities has been given limited attention. The purpose of this study therefore sought to establish teacher factors that create a dilemma in implementing learners' outdoor activities in Hamisi Sub-County, Vihiga County, Kenya. The study adapted a mixed method research design. Maria Montessori theory of children' play was used for the study. Stratified proportionate sampling, simple random, purposive and census techniques were utilized to select the sample size. A sample of 33 ECDE lead teachers, 27 ECDE teacher trainers and 12 learners from a target population of 110 ECDE lead teachers, 27 ECDE teacher trainers and 4400 learners was selected. A questionnaire, interview schedule and observation guide were the instruments to collect data. A pilot study was conducted from the neighbouring Sabatia Sub County to ascertain the strength of the reliability and validity of the instruments. Validity was ensured based on construct and content validity. Reliability was ensured through test-retest technique. A reliability co-efficient of 0.7 using Cronbach's Alpha Coefficient was attained for both instruments and therefore deemed appropriate for use in the actual study. The study enhanced ethical considerations. Qualitative data was analysed using content analysis. Quantitative data was analyzed using descriptive statistics such as frequencies, and percentages and findings presented in pie charts, bar graphs and tables. Inferential statistics ANOVA was used to establish the relationship between independent and dependent variable at 0.05 confidence level. The findings established that pre-school teachers had a negative attitude towards outdoor play activities and concentrated more in teaching academically oriented activity areas at the expense of outdoor play. The results showed a significant difference in the means of the different teacher factors and the implementation of outdoor play activities in the curriculum $\{F(6,25)=2.552, p=.000\}$. Therefore the null hypothesis was rejected and the alternative hypothesis accepted that there is a significant difference in the means of the different teacher factors and the implementation of learners outdoor play activities in the curriculum. The study concluded that ECDE center parents and teachers should discuss the importance of outdoor play activities and let teachers teach them just like other activity areas in ECDE curriculum prepared by Kenya Institute of Curriculum Development. The study recommended that the Quality Assurance and Standards officers should regularly visit ECDE centers and give appropriate guidance to teachers teaching in ECDE centers on importance of outdoor play activities in holistic development of children. The study suggested that A similar study to this study should be carried out in other neighboring sub-counties of Vihiga County.

Keywords: Teacher factors, psychomotor activities, dilemma, curriculum, implementation, play

\section{Introduction}

Teachers of preschool in most parts of the world have acknowledged the pivotal role played by outdoor activities on children development. Some global studies have not only recognized the importance of play on children's' health and growth but also the multiple role of play on children learning outcomes (Heather, Melinda, Ahn, \& Fedewa, 2014; Park \& 
Riley, 2015). As a result instructors are now according children with possibilities for each of the available opportunities, organized and spontaneous play activities.

Julia (2017) note that both the outdoor and indoor psychomotor activities contribute and complement learner's competence development. These mean that both indoor and outdoor play activities should be treated equally in order to provide learners with enough opportunity in both learning environments.

Dowdell, Gray and Malone (2011) established that play activities had an effect on the social behavior of learners. The authors further stated that natural environments had an advance effect on learners' positive relationship with teachers and peers besides providing them with diverse learning environment. Additionally, Greenfield (2004) posits that natural play environment offered learners with learning opportunities that is appropriate for risks taking through games activities. Tomporowski, Davis, Miller and Naglieri (2017) postulate that learners' psychomotor activities assist in improving the functioning of the brain and its cognitive development.

Teacher training in play activities has been considered to encourage utilization of play materials and facilities in teaching. For effective teaching of play activity the preschool teachers should efficiently be trained in order to adapt play as a medium of teaching and learning. In spite of the existing importance of play, most teachers who had trained in computer skills did not actualize it in the classroom methodological approaches (Oliver \& Shapiro, 1993). Therefore, most of the newly employed teachers who had computer knowledge and skills in computer were no different in computer methodological teaching from those who were computer illiterate (Oliver \& Shapiro, 1993). Thus, the foregoing calls for pertinent use of play during both of outdoor and indoor teaching and learning.

According to Perkins, Jacobs, Barber and Eccles, (2004), learners' involvement in play activities is a pivotal predictor of young adults' involvement in sports, games and physical development activities. Learners play activities are associated with improved educational performance and high academic scores.Calbom(2012)postulate that play activities are considered to correlate with cognitive skills, positive attitudes, learning concentration and attention and acquisition of positive classroom behavior).In Britain, Saide (2009) studied teacher's role in children's literature - related play and found out that teachers should act as role models and guide in the process of teaching and learning through literacy related play for effective curriculum implementation in early childhood centers.

Research studies indicate that teachers play a key role in directing or guiding certain instructional goals and objectives on learners' education through play (Lillemyr \& Fredrick, 2003). Goffin and Wilson (2003) assert that teachers have varied roles to support integration of learner's play activities in the Early Childhood Development Education curriculum implementation. This implies that teachers should be able to provide; play materials, structure play environment, and model play, expose learners to play opportunities and encourage good quality play.

According to Social Learning Theory, Papalia (2003) observed that children learn by observing and imitating models and their model in play is the teacher. Therefore the teacher, in terms of play, will be imitated and modeled. Most preschool colleges in the United States and other Western Countries traditionally have followed a child centered philosophy stressing social and emotional growth in line with young children's developmental needs (Papalia, 2003). Some colleges such as those based on the theories of Piaget or the Italian educator Maria Montessori, have a stronger cognitive emphasis. In the US pressures have grown to offer pre-school teacher training instruction on basic academic skills, Academically oriented programs neglect young children's need for exploration and free play and too much teacherinitiated instruction may stifle their interests and interfere with self-initiated learning (Elkind, 2007). This study sought to investigate on influence of outdoor play activities on preschool performance.

During play activities, teacher's dilemma arise because of the arising risks such as accidents, fearful play tags, rough field surfaces and occurrence of death. Large class size and external threats (Simmons, 2010) and society values, cultural beliefs and successive legal complexity (Staempfli, 2009) are other causes of dilemma among teachers during outdoor play activities. However, the use of safe play grounds with a clear policy on effectiveness of outdoor activities can be a mitigation of this dilemma. Teachers can have self-confidence and effective learners' familiarity with outdoor activities when other options have been put in place that limit such fears. This risk reluctant culture (Furedi, 2002; Humberstone \& Stan, 2009) are likely to impede teachers attitudes and application of play activities that are acknowledged to be beneficial to the learners. The psychomotor activities that are generally conducted outside the classroom are considered to be associated with physical and developmental growth of the learners (Ernst, 2013).

Saracho and Olivia (2001) conducted a study in USA on teachers' perceptions in promoting literacy among Spanish speaking learners using play activity. The study established that teachers who adopted play activity during lesson presentation enabled learners to comprehend the language acquisition faster than those who did not use play activities. Though the study was rich in methodology, it however had limited sample size of 40 teachers unlike the current study that had a large sample size of 205 participants. The reviewed literature was conducted in advanced USA while the present study was conducted in developing nation, Kenya. The current study intended to bridge this gap.

Johnas (2013) conducted a study on howteachers' utilize play activities in teaching pre-primary learners in Tanzania. The study made use of Maehr's Personal Investment Theory and descriptive research design. A sample of 30 teachers out the target population of 86 teachers constituted the participants of the study. Teacher's questionnaire and an observation guide were the only toolsused to collect data. The relationship between the independent and dependent variables was determined by use of a Chi- Square at level of significance $0.05(\mathrm{p}<0.05)$. The findings indicated that $58 \%$ of teachers used play as a teaching strategy in contrast to $42 \%$ that ignored the use of play activity in teaching and learning. The finding concluded that there was a significant relationship between teachers use of play activities and learners test scores. Though the methodology used in the study was adequate enough, it however was limited by use of two instruments; questionnaire and observation guide and a sample size 36 respondents as opposed to the present study that used three instruments; questionnaire, interview schedule and observation guide and a large sample of 72respondents 
respectively. The current study used the mixed method design and Maria Montessori's theory as opposed to the aforementioned study. The present study was thus destined to fill this relationship gap.

Wangare (2010) in a study entitled factors hindering play in Makadara District, Nairobi County, Kenya, had a target population of 2608 preschool learners and 180 preschool teachers. The sample for the actual study consisted 300 preschool learner and 18 teachers. The study used a questionnaire as the only tool to collect data. The study established that some teachers used play as punishment for wrong doing among learners and made a recommendation that this kind of punishment that instills fear, anxiety, resentment and hostility towards children' learning should be avoided. Whereas Wangare (2010) used only one tool for data collection, this study used three tools that are questionnaire observation schedule, interview guide to collect data. This study was conducted in a predominantly rural setting as opposed to the reviewed study that was conducted in an urban setting. This forms the relationship gap that this study tried to investigate.

Gordon and Browne (2004) report that teachers are key facilitators of outdoor play activities. A study by Speedlin (2010) in USA on teachers preparation of lesson planning at K-5 elementary level revealed that 50\% of teachers did not plan for outdoor play activities and that $42 \%$ of teachers did not use play during classroom lesson presentation. In South Africa, Imenda (2012) assert that the 71\% teachers who allow learners to pursue their own choice of play activities enable students succeed in academic attainment.

Teachers'use of play can greatly provides the requisite motivation through play to develop preschool leaners talents if and only if they apply appropriate acquired training and experience. A study by Gumo (2003) on the school based factors affecting teaching of Art and Craft among preschool children in Kenya established a significant positive correlation between teaching experience and children Art and Craft scores. Teachers' experience is a key determinant factor in implementation of effective play activity and mitigation upon any arising dilemma.

A study by Tarimo (2013) in Tanzania on the strategies adapted by teachers and how they influence play activities established that a majority of public pre-schools had inadequate and dilapidated play materials as opposed to those in privately owned pre-schools. The study further established that teachers' motivation and training influence the quality of teaching and of play activities in schools. Kerichi (2015) conducted a study on the adequacy and appropriateness of play environment on ECDE physically challenged learners in Kenya. The study concluded that though trained and qualified teachers effectively handled learners with learning difficulties, the teaching play facilities and materials were; inadequate and inappropriate for use by physically challenged learners.

A study carried out by Ng'asike (2004) on use of play by mathematics teachers in Kasarani Sub Count, Nairobi County, in Kenya established that teachers training enabled them to effectively provide child-centered pedagogical methods that enhanced high scores in examinations. On contrary, the above mentioned study indicated that only $10 \%$ of the teachers made use of play as a strategy when teaching pre-school mathematics activity despite their formal training. This dilemma led to detrimental pupils' performance because children were not able to effectively comprehend mathematics concepts.

\section{Research Methodology}

The study sought to investigate on pre-school teachers' dilemma in implementation of learners' psychomotor curriculum in Kenya. The study objective sought to establish influence of teacher factors that create a dilemma in implementing learners' curriculum outdoor activities. The study adapted the mixed methods design. The study had a target population of 110 public primary preschools. Stratified sampling technique was used to select 33 public preprimary schools from which simple random sampling was adapted to identify 33 ECDE lead teachers and purposive sampling technique used to select 12 preschool learners to participate in the study. Census sampling was used to select 27 pre-primary teacher trainers. The study adapted questionnaire, interview schedule and observation guide as tools to collect and aid in data analysis. Face and content validity of research instruments was established by use of university supervisors' experts and a pilot study. Test re-test technique was used to test for instrument reliability. Quantitative and qualitative data were analyzed by use of descriptive and inferential statistics. The findings of the quantitative data generated from closed ended questions were tabulated and presented using frequency distribution tables, cross tabulation tables and percentages. Qualitative data collected from open ended questions was categorized in themes based on the research questions and reported in a narrative form. The ANOVA test was used to determine between teacher factors and preschool learners implementation of curriculum and to test whether the observed relationship is significant or not. The level of significance was set at $\alpha 0.05$.

\section{Findings of the Study}

\subsection{Findings on Teacher Factors That Create a Dilemma in the Implementation of Psychomotor Curriculum}

The research objective was to investigate on the teacher factors that influence implementation of outdoor curriculum activities on pre-school learners in public schools. A questionnaire that was based on a 5-point Likert scale was explored to gather teacher's responses that the researcher used to compute percentage and frequencies on various items as tabulated in Tables 1 . 


\begin{tabular}{|c|c|c|c|c|c|}
\hline Item & SA & $\mathbf{A}$ & $\mathbf{U}$ & D & SD \\
\hline $\begin{array}{l}\text { Pre-school teacher training are mostly } \\
\text { academically oriented, which neglect young } \\
\text { children's need for exploration and free } \\
\text { play. }\end{array}$ & $9(29.0 \%)$ & $\begin{array}{c}8 \\
(25.8 \%)\end{array}$ & $5(16.1 \%)$ & $\begin{array}{c}7 \\
(22.5 \%)\end{array}$ & $2(6.5 \%)$ \\
\hline $\begin{array}{l}\text { There is too much teacher-initiated } \\
\text { instruction which stifles the learner's } \\
\text { interests and interferes with self-initiated } \\
\text { play learning. }\end{array}$ & 7 (22.6\%) & $\begin{array}{c}5 \\
(16.1 \%)\end{array}$ & $3 \quad(9.7 \%)$ & $\begin{array}{c}9 \\
(29.0 \%)\end{array}$ & $\begin{array}{c}7 \\
(22.6 \%)\end{array}$ \\
\hline $\begin{array}{c}\text { I tend to concentrate more on academically } \\
\text { oriented programs at the expense of } \\
\text { psychomotor activities. }\end{array}$ & $\begin{array}{c}11 \\
(35.5 \%)\end{array}$ & $\begin{array}{c}6 \\
(19.4 \%)\end{array}$ & $\begin{array}{c}2 \\
(6.5 \%)\end{array}$ & $\begin{array}{c}5 \\
(16.1 \%)\end{array}$ & $\begin{array}{c}7 \\
(22.6 \%)\end{array}$ \\
\hline $\begin{array}{l}\text { I have negative attitudes towards the } \\
\text { learners' play, though I know it is } \\
\text { important aspect of learning. }\end{array}$ & $\begin{array}{c}14 \\
(45.2 \%)\end{array}$ & $\begin{array}{c}6 \\
(19.4 \%)\end{array}$ & $\begin{array}{c}3 \\
(9.7 \%)\end{array}$ & $\begin{array}{c}4 \\
(12.9 \%)\end{array}$ & $\begin{array}{c}4 \\
(12.9 \%)\end{array}$ \\
\hline $\begin{array}{l}\text { After training, ECDE teachers develop a } \\
\text { negative attitude towards play } \\
\text { concentrating on academic work in order to } \\
\text { attract and be retained by school owners. }\end{array}$ & $\begin{array}{c}13 \\
(41.9 \%)\end{array}$ & $\begin{array}{c}5 \\
(16.1 \%)\end{array}$ & $3 \quad(9.7 \%)$ & $\begin{array}{c}4 \\
(12.9 \%)\end{array}$ & $\begin{array}{c}6 \\
(19.4 \%)\end{array}$ \\
\hline $\begin{array}{l}\text { More practical play activities should be } \\
\text { incorporated in teacher training. }\end{array}$ & $\begin{array}{c}12 \\
(38.7 \%)\end{array}$ & $\begin{array}{c}8 \\
(25.8 \%)\end{array}$ & $\begin{array}{c}4 \\
(12.9 \%)\end{array}$ & $\begin{array}{c}4 \\
(12.9 \%)\end{array}$ & $\begin{array}{c}4 \\
(12.9 \%)\end{array}$ \\
\hline $\begin{array}{l}\text { The role of teachers is highly influenced by } \\
\text { teachers' training, attitude, motivation and } \\
\text { remuneration. }\end{array}$ & $\begin{array}{c}13 \\
(41.9 \%)\end{array}$ & $\begin{array}{c}5 \\
(16.1 \%)\end{array}$ & $\begin{array}{c}3 \\
(9.7 \%)\end{array}$ & $\begin{array}{c}4 \\
(12.9 \%)\end{array}$ & $\begin{array}{c}6 \\
(19.4 \%)\end{array}$ \\
\hline $\begin{array}{l}\text { I understand the importance of play in } \\
\text { learning. }\end{array}$ & $\begin{array}{c}10 \\
(32.2 \%) \\
\end{array}$ & $\begin{array}{c}12 \\
(38.7 \%) \\
\end{array}$ & $\begin{array}{c}0 \\
(0.0 \%) \\
\end{array}$ & $\begin{array}{c}5 \\
(16.1 \%) \\
\end{array}$ & $\begin{array}{c}4 \\
(12.9 \%) \\
\end{array}$ \\
\hline $\begin{array}{l}\text { I sometimes use play as punishment for } \\
\text { wrong doing and therefore makes play look } \\
\text { punitive. }\end{array}$ & $\begin{array}{c}10 \\
(32.2 \%)\end{array}$ & $\begin{array}{c}6 \\
(19.4 \%)\end{array}$ & $3 \quad(9.7 \%)$ & $\begin{array}{c}8 \\
(25.8 \%)\end{array}$ & $\begin{array}{c}4 \\
(12.9 \%)\end{array}$ \\
\hline $\begin{array}{c}\text { I consider play as less effective method of } \\
\text { teachers. }\end{array}$ & $9(29.0 \%)$ & $\begin{array}{c}7 \\
(22.6 \%) \\
\end{array}$ & 2 (6.5\%) & $\begin{array}{c}8 \\
(25.8 \%)\end{array}$ & $\begin{array}{c}5 \\
(16.1 \%) \\
\end{array}$ \\
\hline $\begin{array}{l}\text { My age influence my participation in } \\
\text { psychomotor activities. }\end{array}$ & $7(22.6 \%)$ & $\begin{array}{c}8 \\
(25.8 \%)\end{array}$ & $5(16.1 \%)$ & $\begin{array}{c}5 \\
(16.1 \%)\end{array}$ & $\begin{array}{c}6 \\
(19.4 \%)\end{array}$ \\
\hline $\begin{array}{c}\text { My gender influences my participation in } \\
\text { psychomotor activities. }\end{array}$ & $\begin{array}{c}14 \\
(45.2 \%)\end{array}$ & $\begin{array}{c}9 \\
(29.0 \%)\end{array}$ & $\begin{array}{c}1 \\
(3.2 \%)\end{array}$ & $\begin{array}{c}3 \\
(9.7 \%)\end{array}$ & $\begin{array}{c}4 \\
(12.9 \%)\end{array}$ \\
\hline
\end{tabular}

Table 1: Lead Teachers' Perception on Teachers Factors on Implementation of Psychomotor Activities in the ECDE Curriculum ( $N=31$ )

SA-Strongly Agree A-Agree, N-Neutral, and D-Disagree and SD-Strongly Disagree

The findings of the study show that although pre-primary teachers agree that psychomotor play and physical activities are important educational processes which foster mental, physical, social, emotional and creative growth of a pre-primary learner, implementation of psychomotor activities in pre-primary curriculum in Hamisi Sub-county is still far from being achieved. For instance, significant majority, 70.9\% (22) of the pre-primary lead teachers who were sampled for the study generally accepted most teachers understand the importance of play in learning. This findings concur with Heather, Melinda, Ahn and Fedewa (2014) and Park and Riley(2015) who agree that some global studies have not only recognized the importance of play on children's' health and growth but also the multiple role of play on children learning outcomes

However, 64.6\% (20) of them confirmed that they had negative attitudes towards outdoor activities, though they knew it was an important aspect of learning. They argue that outdoor activities waste important time for both the teacher and the learners. This study concurs with assertion by Lewin (2007) who notes that doing the same thing repeatedly like class repetition is boring. The findings of Lester and Russel (2008) also corroborate that evidence of minimal time allocated to play activities exists at the expense of examination oriented curriculum.

From the findings of the study, it was discovered that pre-unit teachers tend to concentrate more on academically oriented programs that are indoor than the expense of outdoor play activities. This was reflected by $35.5 \%$ (11) of the ECDE lead teachers who took part in the study who strongly agreed to the researchers' assertion that some preschool teachers concentrate more in academic work than play activities. Only about a fifth, 22.6\% (7), of the preschool teacher respondents negated the claim that more time is spent in academic work than psychomotor activities. One teacher confided with the researcher said; "The Head teacher says that parents complain of learners who complete preschool yet they are not academically endowed to either read or do simple Arithmetic. The learners therefore have to use available time to read - PE time and for 30 minutes after lunch" (LT, 31).The sentiments above agree with Saide (2009) who noted that certain subjects are taught in schools at the expense of others. Similar the findings of Elkind (2008), agree by positing that play is no longer valued in educational activity areas.Elkind(2007) further concur that academically oriented programs 
neglect young children's need for exploration and free play and too much teacher-initiated instruction may stifle their interests and interfere with self-initiated learning.

It came out from the results of the survey that, although considerable proportion of the preschool teachers who participated in the study opined that preschool training gives equal time in academics and outdoor activities, a sizeable proportion of them agree that most ECDE teachers develop negative attitudes towards outdoor activities thereafter. This point of view was reflected by more than a quarter, $29.0 \%$ (9), of the lead teachers who vehemently refuted the researcher's assertion that pre-school teacher training are mostly academically oriented and neglect young children's needs for exploration and free play. However, it came out clearly from the findings of the study that after training, some ECDE teachers develop a negative attitude towards play and do concentrate more on academic work in order to give good academic performance for the purpose of attracting and retaining more children in the learning centres. The finding agree with Furedi (2002)and Humber stone and Stan (2009) who noted that the risk reluctant culture are likely to impede teachers attitudes and application of play activities that are acknowledged to be beneficial to the learners.

Nonetheless, nearly two thirds $64.5 \%$ (20) of the lead teachers who were sampled for the study agreed that more practical play activities should be incorporated in teacher training, to enhance the teachers' skills, knowledge and attitudes in play learning among the ECDE learners. The finding confirms Oliver and Shapiro (1993) who postulated that most teachers who had trained in computer skills did not actualize it in the classroom methodological approaches.Lillian (2010) further opine that most teachers consider outdoor play activities as a waste of learners time and therefore concentrated on learners classroom indoor academic performance.

Further, it emerged from the results of the survey that some teachers use play as punishment for wrong doing and therefore make play look punitive and arduous activity. This was indicated by slightly more than a half, 51.6\% (16), of the lead teacher respondents who confirmed that some of them use some play as a form of punishment. This deters positive incorporation of outdoor play activities in the ECDE curriculum. The findings agree with those of Wangare (2010) who established that some teachers used play as punishment for wrong doing among learners and made a recommendation that this kind of punishment that instills fear, anxiety, resentment and hostility towards children' learning should be avoided.

However, another group [22.6\% (7)] of the lead teachers who took part in the study who said that teachers do allow ECDE learners to indulge in outdoor activities, held a general perception that sometimes there is too much teacherinitiated instruction which instead stifle the learners interests and interfere with self-initiated play learning. This is contrary to the generally held belief that for outdoor play activities to be meaningful, the teacher should only guide, provide suitable equipment and ensure the safety of children. The teacher should be present during the playing only to supervise, give direction, give guidance, identify and nurture talent and take precautionary measures to avoid injuries. The teacher should give opportunity for the learners to explore and exhibit their creativity and innovativeness. This findings are in line with Saide (2009) who stated that during children's related pay activities, the teacher's role is to act as role models and guide in the process of teaching and learning through literacy related play for effective curriculum implementation in early childhood centers. The finding confirms Millicent (2010) who provides a reason that most teachers lay much emphasis on indoor academic activities than the outdoor play activities.

On the flip flop, the findings of the study revealed that majority 58.0\% (18) of the lead teachers who took part in the study affirmed that the role of teacher is highly influenced by teacher's characteristics such as teacher training, attitude, motivation and remuneration. The finding affirms Oliver and Shapiro (1993) who established that for effective teaching of play activities, the preschool teachers should efficiently be trained in order to adapt play as a medium of teaching and learning.

Additionally, age and gender of the ECDE teacher was established to have bearing on the teacher's inclination on use of outdoor activities. For instance, slightly more than one out of every two lead teachers who were surveyed for the study agreed that teachers' age affect their participation in outdoor activities. On the same note, about three quarters, $74.2 \%$ (23), of the lead ECDE teachers respondents were also convinced that teachers' gender affect teachers participation in outdoor activities. Only 35.5\% (11) of the lead teachers negated the claim that age and gender of the ECDE teacher affect his/her incorporation of outdoor activities into the ECDE curriculum. The implication of this finding is that, it is important for preschool teachers to understand the role of various outdoor play and physical activities and be able to select suitable ones appropriate for their learners' varied ages. One of the Lead Teachers retorted: "We used to teach Physical Activities daily. We got frustrated. This is my $45^{\text {th }}$ year and 22 years doing the same thing. I now teach with my former pupil who is younger than me by far. She is sick today. She will take them out tomorrow. How do you expect me to jump with pupil yet there is a younger teacher here?" (LT, 29).

Another Lead teacher 16, cited age and tiredness. The respondent reasoned that it is not wise to keep on jumping in the field with kids when there were younger teachers who should jump with learners. The teacher also affirmed having the colleague teacher on the same staff. The findings are consistence with Ng'asike (20014) and Kingi (2018) who established that teacher's age, gender, academic qualifications and work experience are significantly related to learner's educational performance.

\subsection{Testing for Hypothesis}

The study also tested for the following null hypothesis:

- $\mathrm{H}_{0 \mathrm{I}}$ : There is no significant influence of teacher factors creating a dilemma in the implementation of psychomotor activities in the curriculum'

The hypothesis was tested using ANOVA to establish the relationship that existed between teacher factors creating a dilemma and the implementation of learners' psychomotor activities in the curriculum. The relationship between the 
independent and dependent variables was determined at level of significance $0.05(\mathrm{p}<0.05)$. The findings are represented in Table 2.

\begin{tabular}{|c|c|c|c|c|c|}
\hline & Sum of Squares & df & Mean Square & F & Sig. \\
\hline Between Groups & 7181.808 & 6 & 1196.968 & 2.552 & .000 \\
\hline Within Groups & 6481.183 & 25 & 259.2473 & & \\
\hline Total & 13662.991 & 31 & & & \\
\hline
\end{tabular}

Table 2: ANOVA Testing for Teacher Factors and the Implementation of

Psychomotor Curriculum Activities

The results showed a significant difference in the means of the different teacher factors and the implementation of outdoor play activities in the curriculum $\{F(6,25)=2.552, p=.000\}$. Therefore, the null hypothesis was rejected and the alternative hypothesis accepted that there is a significant influence of teacher factors creating a dilemma in the implementation of learners' psychomotor activities in the curriculum. The finding confirms Johnas (2013) whose study concluded that there was a significant relationship between teachers' use of play activities and good learners test scores.

\section{Conclusions}

The study investigated teacher factors that create a dilemma in the implementation of outdoor play curriculum activities. The findings established that pre-school teachers concentrated more in teaching academically oriented activity areas at the expense of outdoor play. It also established that pre-school teachers develop a negative attitude towards outdoor play activities for the reasons that it was tiresome and physically involving a lot of energy. The results of their not teaching outdoor play were to enhance performance in the academically oriented activity areas' performance. It was further established that some teachers used play as punishment for wrong doing and therefore made play look punitive and arduous activity. It also came out that the teachers role was highly influenced by teacher characteristics like teachertraining, motivation and remuneration.

The results showed a significant difference in the means of the different teacher factors and the implementation of outdoor play activities in the curriculum $\{F(6,25)=2.552, p=.000\}$. Therefore the null hypothesis was rejected and the alternative hypothesis accepted that there is a significant difference in the means of the different teacher factors and the implementation of learners outdoor play activities in the curriculum.

\section{Recommendation}

The study recommended that ECDE teachers' training college personnel should enhance the teaching of practical outdoor play activities to their students not only for examination purpose but also for life.

\section{Suggestions for Further Research}

The study suggested that a similar study should be carried out in other areas or locales.

\section{References}

i. Calbom, L. (2012). K-12 Education: School-Based Physical Education and Sports

ii. Programs. Report to Congressional Requesters. GAO-12-350.US Government Accountability Office.

iii. Dowdell K, Gray T \& Malone K 2011. Nature and its influence on children's outdoor

iv. play. Australian Journal of Outdoor Education, 15(2):24-35.

v. Elkind, D. (2007). The Power of Play: How Spontaneous Imaginative Activities lead to

vi. Happier. Healthier Children. New York: Knopf.

vii. Ernst, J. (2013). Early childhood educators' use of natural settings as learning environments: an exploratory study of beliefs, practices, and barriers. Environmental Education Research, 20(6), 735-752.

viii. Furedi, F. (2002). Culture of fear: Risk taking and the morality of low expectation. London, Continuum Books.

ix. Goffin, G. and Wilson, C. [2002]. Curriculum Models and Early Childhood Education: Education: Appraising the Relationship (2nd Ed) Upper Saddle River NIJ: Merril Prentice Hall.

$x$. Gordon, A. \& Browne, K. (2004). Beginnings and beyond: Foundations in early childhood education (6th ed.). New York: Delmar.

xi. Greenfield C 2004. Can run, play on bikes, jump the zoom slide, and play on the swings: exploring the value of outdoor play. Australian Journal of Early Childhood, 29 (2):1-5.

xii. Gumo, A.W.M. (2003). Teachers" Factors Related To the Teaching of Art and Craft in Pre- Schools in Kaloleni and Kikambala Division in Kilifi District. Kenyatta University. (Un Published Masters Thesis. Kenyatta University).

xiii. Heather, E., Melinda, H., Ahn, S., \& Fedewa, A. (2014). Impact of recess interventions on children's physical activity: A meta-analysis. American Journal of Health Promotion, 28(3), 159-167.

xiv. Humbestone, B., \& Stan, I. (2009) Well-being and outdoor pedagogies in primary schooling: The nexus of wellbeing and safety. Australian Journal of Outdoor Education, 13 (2).

$\mathrm{xv}$. Johnas, T.J. (2013)Teachers' use of play as a teaching strategy in pre-primary schools in

xvi. Mwanga district, Kilimanjaro region, Tanzania (Unpublished master's thesis) Kenyatta University, Kenya.

xvii. Julia, K. (2017) Indoor and Outdoor Play in Preschool Programs. Universal Journal of Educational Research 5(4): 641-647. 
xviii. Kerich, M.E (2015) The Availability and Suitability of Outdoor Play Environment for the Physically Challenged Children in Kisumu City ECD Centres. American Journal of Educational Science Vol. 1, No. 4, 2015, pp. 165-170.

xix. Lillemyr, C. and Ole-Fredrick, P. [2003]. Play in School-The Teachers' Reforms and Recent Research in Contemporary Perspectives on Play in Early Childhood Education (Pp.53- 73). Greenwich, CT: Information Age Publishing.

xx. Ng'asike, J. T. (2004). Teacher"s Use of Play as Medium of Bridging Pre-School

xxi. Children's Mathematical Experiences: A Study of Kasarani Division, Nairobi, Kenya. Un Published M.Ed. Thesis, Kenyatta University.

xxii. Ochanda, E.A. (2015) Effect of play equipment on preschool children's participation in outdoor play activities in Suba East Division, Migori County (Unpublished, Masters thesis) University of Nairobi, Kenya.

xxiii. Olivier, T.A., \& S. (1993). Self - Efficacy and Computers. Journal of Computer - Based Instruction, 20 (3). 81 - 85.

xxiv. Papalia, D. Gross, D. and Feldman, R. (2003).Child Development: A Topical Approach.

xxv. Park, M.-H., \& Riley, J. (2015). Play in natural outdoor environments: A healthy choice.

xxvi. Perkins, D. F., Jacobs, J. E., Barber, B. L. \& Eccles, J. S. (2004). Childhood and adolescent sports participation as predictors of participation in sports and physical fitness activities during young adulthood. Youth \& Society, 35(4), 495-520.

xxvii. Saide, 0. (2009). A Study on the Difficulties Faced by Preschool Teachers in the Planning and Implementation. Gazi University Journal of International Social Research Download online on 30 th July 2015.

xxviii. Saracho, Z. and Olivia, N. [2001]. Teachers' Perceptions of their Roles in Promoting

xxix. Literacy in the Context of Play in A Spanish-Speaking Kindergarten International Journal of Early Childhood, $33(2), 18-31$

xxx. Simmons, D. (2010). Using Natural Settings for Environmental Education: Perceived Benefits and Barriers. The Journal of Environmental Education, 29(3), 23-32.

xxxi. Staempfli, M. (2009). Reintroducing Adventure into Children's Outdoor Play Environments. Environment \& Behaviour, 41, 268-280.

xxxii. Tarimo, J.J. (2013) Teachers' use of play as a teaching strategy in pre-primary schools in

xxxiii. Mwanga district, Kilimanjaro region, Tanzania (Unpublished, Master's Thesis) Kenyatta University, Kenya.

xxxiv. Tomporowski, P. C. Davis, P. Miller, J. Naglieri (2017). Exercise and Children's Intelligence, Cognition, and Academic Achievement, Educational Psychology Review, Vol. 20, No. 2, 111-131.

xxxv. Wangare, M.N. (2010). Factors Hindering Outdoor Play in Makadara District, NairobiCounty. Unpublished Thesis. Nairobi: University of Nairobi. 